\title{
A semiempirical quantum approach to possible structures of copper electrodeposits at submonolayer and monolayer levels on $\mathrm{Pt}(100)$ and $\mathrm{Pt}(111)$ clusters
}

\author{
M.B. López, G.L. Estiú, E.A. Castro and A.J. Arvia \\ Instituto de Investigaciones Fisicoquímicas Teóricas y Aplicadas (INIFTA), Facultad de Ciencias Exactas, \\ Universidad Nacional de La Plata, Sucursal 4, Casilla de Correo 16, (1900) La Plata, Argentina
}

Received 21 January 1992; accepted for publication 2 June 1992

\begin{abstract}
The development and reconstruction of surface structures formed by underpotential deposition (UPD) of Cu atoms on Pt(100) and $\mathrm{Pt}(111)$ clusters are approached through extended Hückel molecular orbital (EHMO) calculations applied to a statistical Cu atom deposition. These results allow us to obtain a qualitative description of the different stable configurations of $\mathrm{Cu}$ atoms on the Pt cluster surfaces in terms of the corresponding binding energies.
\end{abstract}

\section{Introduction}

The underpotential deposition (UPD) of atoms on a foreign metal substrate changes its electronic and structural characteristics, a fact which is interesting from the standpoint of heterogeneous catalysis including electrocatalysis [1-5]. The UPD of a foreign metal on noble metal electrodes has been extensively investigated $[1,4,9-12]$, particularly in relation to its influence on the electro-oxidation of small molecules such as $\mathrm{CO}$ on $\mathrm{Pt}$ in acid solutions [4]. It should be noted that the complex structure of the electrochemical interface depends on both the electrode material and its structure, and the constituents of the solution in contact with the electrode. Accordingly, an electrochemical adsorbate-substrate system becomes more complex than the corresponding metal/gas system.

On the other hand, the knowledge of bimetallic structures at submonolayer and monolayer ranges provides new insights for those processes leading to surface reconstruction of the substrate (6-8). Thus, the UPD of $\mathrm{Cu}$ on Pt produces a bimetallic $\mathrm{Pt}_{N} \mathrm{Cu}_{L}$ system in contact with an aqueous electrochemical environment, a process which implies potential and crystalline face dependent interactions between $\mathrm{Cu}$ and $\mathrm{Pt}$ atoms. Although for such a bimetallic system no definite vertical reconstruction has been concluded from either voltammetric [12] or optical [10,11] data, it appears that metastable bimetallic structures are initially produced and changed into other more stable ones. This type of surface reconstruction which is feasible when the interaction energy among substrate and UPD layer atoms becomes comparable to the interaction energy among atoms at the proper UPD metal layer, can be statistically described as a phase transition [1316]. As a first approach foreign metal UPD on a metal substrate can be compared to a gas phase adsorption process influenced by the magnetization of the substrate $[17,18]$. In this case, $M_{\mathrm{S}}$, the magnetization saturation of the system, can be approximately expressed as an excess of $S$, the spin of electrons in the metal [18]:

$M_{\mathrm{S}} \cong S^{\uparrow}-S_{\downarrow}$,

where the arrows denote the spin directions. Accordingly, the adsorption of the foreign atom can be related to changes in the spin distribution of surface atoms. Therefore, the change in magneti- 
zation can be regarded as the driving force leading to surface rearrangements at adsorbate-substrate domains. This type of process becomes extremely important in dealing with adsorbates such as the open-shell-high-electron-number transition metals.

Magnetization changes are usually described within a statistical framework, although this approach is rather limited for a quantitative description of structural characteristics of metal deposits, it allows one to envisage the microscopic mechanism of metal surface restructuring.

The present work refers to a molecular orbital calculation related to $\mathrm{Cu}$ UPD on $\mathrm{Pt}(100)$ and $\mathrm{Pt}(111)$ under different applied electric potentials to determine as a first approach the stability of the different structures emerging after a certain number of UPD $\mathrm{Cu}$ atoms has been accumulated on the Pt single crystal surface. The extended Hückel molecular orbital (EHMO) data presented in this work qualitatively accounts for the structural modifications of UPD $\mathrm{Cu}$ deposits on Pt which have been experimentally determined [19], and provides an explanation for the driving force operating the surface rearrangement at the $\mathrm{Cu}$ submonolayer level. The results derived from EHMO calculations are limited to establish only qualitative trends related to the influence of the structural parameters on the stability of different surface atom configurations. Accordingly, the MO interpretations of those calculations have only a qualitative predictive capacity.

\section{Calculation procedure}

For the EHMO method used in this work [20], one electron orbital attractive energies and core-core interatomic repulsive interactions are considered [21]. The off-diagonal energy matrix term, $H_{i j}$ is multiplied by an $\exp \left(-0.13 R_{a b}\right)$ term to allow the interaction energy to decrease as $R_{a b}$ increases. In this way it is possible to correct the long tailed diatomic dissociation curve resulting from standard EHMO methods.

The attractive component energy matrix elements are:

$$
\begin{aligned}
& H_{i i}^{a a}=-(\mathrm{VSIP})_{i}^{a}, \\
& H_{i j}^{a a}=0 \\
& H_{i j}^{a b}=1.125\left(H_{i i}^{a a}+H_{j j}^{b b}\right) S_{i j}^{a b} \exp \left(-0.13 R_{a b}\right),
\end{aligned}
$$

where $i$ and $j$ denote atomic orbitals, and $a$ and $b$ correspond to different atoms. VSIP stands for the valence state ionization potential; $S_{i j}$ is the overlap integral involving orbital $i$ on center $a$, and orbital $j$ on center $b ; R_{a b}$ is the internuclear distance between centers $a$ and $b$. The VSIP's are experimentally based [22,23] and valence orbitals are of the Slater's form with exponents based on SCF calculations [24-27].

Initially $\mathrm{Cu}$ atoms occupy the most reactive sites on Pt. At the electrochemical interface the

\begin{tabular}{|c|c|c|c|c|c|c|c|c|c|c|c|c|c|}
\hline \multirow[t]{2}{*}{ Atom } & \multirow[t]{2}{*}{ System } & \multicolumn{3}{|l|}{$\mathbf{s}$} & \multicolumn{3}{|l|}{$\mathrm{p}$} & \multicolumn{6}{|l|}{ d } \\
\hline & & $\bar{n}$ & $\zeta$ & VSIP $(\mathrm{eV})$ & $n$ & $\zeta$ & VSIP $(e V)$ & $n$ & $\xi_{1}$ & VSIP (eV) & $C_{1}$ & $C_{2}$ & $\xi_{2}$ \\
\hline \multirow[t]{3}{*}{$\mathrm{Pt}$} & (A) & 6 & 2.550 & -8.96 & 6 & 2.250 & -4.92 & 5 & 6.013 & -9.56 & 0.6567 & 0.5715 & 2.390 \\
\hline & (B) & 6 & 2.850 & -10.95 & 6 & 2.550 & -6.91 & 5 & 6.313 & -11.55 & 0.6567 & 0.5715 & 2.420 \\
\hline & (C) & 6 & 2.850 & -11.35 & 6 & 2.550 & -7.31 & 5 & 6.013 & -11.95 & 0.6567 & 0.5715 & 2.420 \\
\hline \multirow[t]{3}{*}{$\mathrm{Cu}$} & (A) & 4 & 1.850 & -7.77 & 4 & 1.550 & -3.98 & 3 & 5.950 & -11.96 & 0.5589 & 0.5878 & 2.100 \\
\hline & (B) & 4 & 2.150 & -9.58 & 4 & 1.850 & -5.79 & 3 & 6.250 & -12.50 & 0.5589 & 0.5878 & 2.600 \\
\hline & (C) & 4 & 2.150 & -9.58 & 4 & 1.850 & -5.79 & 3 & 6.250 & -12.50 & 0.5589 & 0.5878 & 2.600 \\
\hline
\end{tabular}

Table 1

Atomic parameters used in the calculation

(A) $\mathrm{Pt}_{N} \mathrm{Cu}_{L}$ system (metal vacuum).

(B) $\mathrm{Pt}_{N} \mathrm{Cu}_{L}$ in aqueous media.

(C) $\mathrm{Pt}_{N} \mathrm{Cu}_{L}$ in aqueous media and UPD conditions.

$n=$ principal quantum number for $s$ and p orbitals, $\zeta=$ Slater orbital exponent, VSIP $=$ valence state ionization potential, $C_{1}$ and $C_{2}$ are linear coefficients. 
simultaneous interaction of $\mathrm{Cu}$ atoms, water molecules and $\mathrm{Pt}$ sites defines an adsorption ensemble characterized by a specific VSIP value. The latter is related to the equilibrium potential of the system. The VSIP value results when the charge transfer at the equilibrium distance of each internuclear bond is close to that predicted by the electronegativity difference of the diatomic bond resulting from Pauling's ionicity relationship [28]. Values assembled in table 1 define the zero potential conditions (reference potential) of the system.

The application of an electric potential can be simulated by either decreasing or increasing the VSIP's (table 1) for either positive or negative Pt surface charging, respectively. Various semiempirical approaches for the band shift caused by electric charging have been used for describing several electrochemical systems [29-33] including surface dopant effects [33,34]. According to one of them VSIP changes of $\pm 1.0 \mathrm{eV}$ can be arbitrarily correlated to $\pm 1.0 \mathrm{~V}$ changes in the reference potential. Correspondingly, as the standard cquilibrium potential of the $\mathrm{Cu} / \mathrm{Cu}^{2+}$ elcctrode is $E^{0}\left(\mathrm{Cu} / \mathrm{Cu}^{2+}\right)=0.34 \mathrm{~V}$ (versus the standard hydrogen electrode), for attaining $\mathrm{Cu}$ UPD conditions the Fermi level of $\mathrm{Pt}$ has been set $0.4 \mathrm{eV}$ above the reference potential.

Our metal atom clusters are high spin, meaning each d-band molecular orbital is occupied by at least one electron. Thus, while lower levels are doubly occupied, some other ones are singly occupied. The result is that the clusters have spin magnetic moments approximating bulk values. Bulk superimposable $\mathrm{Pt}_{N}$ clusters, $N$ being equal to 25 for the $\mathrm{Pt}(100)$ and 24 for $\mathrm{Pt}(111)$, respectively (fig. 1), are used to model the Pt surfaces. The clusters are geometrically built up with the $\mathrm{Pt}-\mathrm{Pt}$ bond length constant at $0.277 \mathrm{~nm}$. The latter which has been used in previous calculations [29] agrees with the $\mathrm{Pt}-\mathrm{Pt}$ interatomic distance in bulk Pt.

From the standpoint of the calculation procedure the initial growth of $\mathrm{Cu}$ deposit on $\mathrm{Pt}$ single crystals can be described, in principle, as an equilibrium adsorption process on a surface where all $\mathrm{Pt}$ atoms are represented by the $\left[(\mathrm{Xe}) 4 \mathrm{f}^{14} 5 \mathrm{~d}^{10}\right]$ electronic structure.

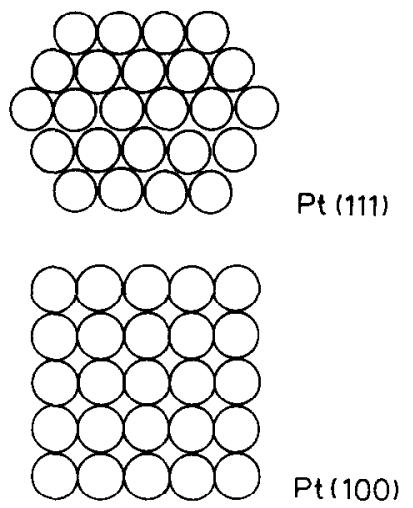

Fig. 1. Schemes of atom surface layers describing $[\mathrm{Pt}(111)]_{24}$ and $[\operatorname{Pt}(100)]_{25}$.

Different types of adsorption sites can be defined on the surface of Pt single crystal structures, namely, top, bridge, and hollow sites. The latter are considered as equivalent and undistinguishable sites where $\mathrm{Cu}$ atom adsorption takes place. This situation remains until either $\mathrm{a} \mathrm{Cu}_{3}$ or a $\mathrm{Cu}_{4}$ hollow site is formed. In this case two distinguishable and non-equivalent adsorption sites compete for the attachment of the incoming $\mathrm{Cu}$ atom.

The unpaired spin electronic configuration of $\mathrm{Cu}$ atoms [(Ar)3 $d^{10} 4 s^{1}$ ] is that of a fermionic system. Therefore, all adsorbed $\mathrm{Cu}$ fermions at the first adsorbate layer can be similarly oriented. No adsorbate-substrate spin pairing is possible when $\mathrm{Cu}$ atoms adsorb on $\mathrm{Pt}\left[(\mathrm{Xe}) 4 \mathrm{f}^{14} 5 \mathrm{~d}^{10}\right]$ atoms. For $L$, the number of $\mathrm{Cu}$ atoms adsorbed, a multiplicity $m=L+1$ characterizes the first adsorbed layer. Hence, the high multiplicity of the $\mathrm{Cu}$ atom overlayer pushes the electronic spin of the incoming $\mathrm{Cu}$ atom in a direction opposite to that defining the first layer. Furthermore, when $\mathrm{Cu}$ atom aggregate structures are being formed on the Pt surface, they can reconstruct to a new one through spin pairing leading to a decrease in the total energy (fig. 2).

The preceding approach can be extended to the UPD of $\mathrm{Cu}$ at the electrochemical interface under the simplest assumption that the presence of water molecules modifies uniformly the surface energy charecteristics of both $\mathrm{Pt}$ and $\mathrm{Cu}$ atoms. For the growth of the $\mathrm{Cu}$ overlayer on $\mathrm{Pt}$ a 


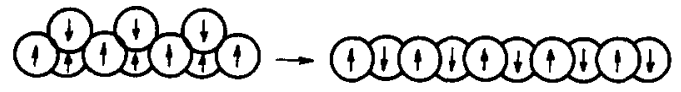

(a)

(b)

Fig. 2. Scheme of a 2D atom monolayer rearrangement leading to a minimum energy spin configuration. (a) $L=10=$ $7^{\uparrow}+3_{\downarrow}$, (b) $L=10=5^{\uparrow}+5 \downarrow$.

statistical model based upon molecular orbital calculations can be advanced, as the latter allows one to evaluate the stability of several $\mathrm{Pt}_{N} \mathrm{Cu}_{L}$ surface structures for different applied electric potentials.

\section{Results and interpretation}

For both $[\operatorname{Pt}(111)]_{24}$ and $[\operatorname{Pt}(100)]_{25}$ surfaces with $N \mathrm{Pt}$ atoms at the interacting surface, $\mathrm{BE}(L)$, the $\mathrm{Pt}-\mathrm{Cu}$ binding energy in the $\mathrm{Pt}_{N} \mathrm{Cu}_{L}$ surface system, decreases according to $\mathrm{CN}$, the coordination number of the adsorption site (table 2), $\mathrm{Cu}$ atom deposition is, in principle, favored on Pt sites with the highest $C N$ values, i.e., the site properties become important for defining the stability of the adsorbate structure. As previously discussed $[35,36]$ the latter is also slightly influenced by underlaying $\mathrm{Pt}$ atoms. However, it is possible to overcome this drawback by considering a sufficiently large monolayer $\mathrm{Pt}$ surface for modeling the adsorption of several $\mathrm{Cu}$ atoms.

The $\mathrm{Cu}$ monolayer on $\mathrm{Pt}$ is built up through the successive addition of $\mathrm{Cu}$ atoms, and correspondingly, the $\mathrm{BE}(L)$ 's for $\mathrm{Cu}$ atoms on either $[\mathrm{Pt}(111)]_{24}$ or $[\mathrm{Pt}(100)]_{25}$ decrease as $L$ increases. Thus, when the $\mathrm{Cu}$ atom coverage becomes suffi-

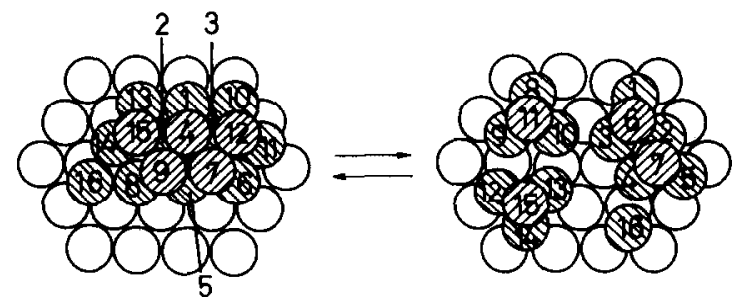

Fig. 3. Structures resulting from the sequential attachment of $16 \mathrm{Cu}$ atoms (numbered and dashed circles) on $[\mathrm{Pt}(111)]_{24}$. The possible $\mathrm{Cu}$ atom rearrangement has been calculated at 0.4. V. spin down; spin up.

ciently large to make $\mathrm{BE}(L)$ smaller than $\mathrm{BE}(\mathrm{Cu}-\mathrm{Cu})$, the $\mathrm{Cu}-\mathrm{Cu}$ atom binding energy, the second $\mathrm{Cu}$ atom layer starts to grow.

Although preferred $\mathrm{Cu}$ atom adsorption always takes place on higher $\mathrm{CN}$ sites regardless the number of $\mathrm{Cu}$ atoms previously adsorbed, the $\mathrm{Cu}$ monolayer growth also implies the appearance of different $\mathrm{Cu}$-adsorption sites. For each value of $L$, however, the $\mathrm{BE}(L)$ value depends on the substrate structure. Thus, the value of $\mathrm{BE}(L)$ for $\mathrm{CN}=4$ on $[\mathrm{Pt}(100)]_{25}$ is greater than the value of $\mathrm{BE}(L)$ for $\mathrm{CN}=3$ on $[\mathrm{Pt}(111)]_{24}$. This difference is reflected through the structure of $\mathrm{Cu}$ adsorbed layers. Thus, for $[\operatorname{Pt}(100)]_{25}$ the higher the $\mathrm{BE}(L)$ value the greater the trend of $\mathrm{Cu}$ atoms to occupy $N=4$ sites. Conversely, for $[\mathrm{Pt}(111)]_{24}$, as soon as a $\mathrm{Cu}_{3}$ site has been formed $\mathrm{Pt}_{3}$ and $\mathrm{Cu}_{3}$ sites are competing for the adsorption of $\mathrm{Cu}(4)$ (tables 3 and 4).

The stabilization energy of different $\mathrm{Cu}$ adsorbate structures resulting when the second $\mathrm{Cu}$ layer starts to grow at $0.4 \mathrm{~V}$ is assembled in table 3. Accordingly, the first and the second $\mathrm{Cu}$ atom

Table 2

$\mathrm{BE}(L)$ values for $\mathrm{Cu}(1)$ on $\mathrm{Pt}(100)$ and $\mathrm{Pt}(111)$ surface sites as a function of the applied electric potential for $N=4$ [35]

\begin{tabular}{|c|c|c|c|c|c|c|}
\hline \multirow{3}{*}{$\begin{array}{l}\text { Adsorption } \\
\text { site }\end{array}$} & \multicolumn{6}{|c|}{$\mathrm{BE}(L)(\mathrm{eV})$} \\
\hline & \multicolumn{2}{|l|}{$-0.6 \mathrm{~V}$} & \multicolumn{2}{|l|}{$0.4 \mathrm{~V}$} & \multicolumn{2}{|l|}{$1 \mathrm{~V}$} \\
\hline & $\overline{\operatorname{Pt}(100)}$ & $\overline{\operatorname{Pt}(111)}$ & $\operatorname{Pt}(100)$ & $\overline{P t(111)}$ & $\overline{P t(100)}$ & $\operatorname{Pt}(111)$ \\
\hline Top & 0.978 & 0.706 & 1.657 & 1.297 & 2.921 & 2.623 \\
\hline Bridge & 1.342 & 0.826 & 1.962 & 1.468 & 3.216 & 2.835 \\
\hline Hollow & 1.728 & 1.049 & 2.256 & 1.653 & 3.629 & 3.032 \\
\hline
\end{tabular}


Table 3

$\mathrm{BE}(L)$ values for $\mathrm{Cu}$ atom surface structures on $[\mathrm{Pt}(111)]_{24}$ hollow sites according to the sequential attachment numbers shown in fig. 3

\begin{tabular}{|c|c|c|c|c|c|c|}
\hline \multirow{3}{*}{$\begin{array}{l}\text { Cu atom } \\
L\end{array}$} & \multicolumn{6}{|c|}{ Electrode potential } \\
\hline & \multicolumn{2}{|l|}{$-0.6 \mathrm{~V}$} & \multicolumn{2}{|l|}{$0.4 \mathrm{~V}$} & \multicolumn{2}{|l|}{$1.0 \mathrm{~V}$} \\
\hline & $\overline{\mathrm{BE}(L)(\mathrm{eV})}$ & $\Delta \mathrm{BE}(L)(\mathrm{eV})$ & $\mathrm{BE}(L)(\mathrm{eV})$ & $\Delta \mathrm{BE}(L)(\mathrm{eV})$ & $\mathrm{BE}(L)(\mathrm{eV})$ & $\Delta \mathrm{BE}(L)(\mathrm{eV})$ \\
\hline 1 & 1.435 & & 2.044 & & 3.323 & \\
\hline 2 & 1.436 & -0.22 & 1.993 & -0.17 & 3.053 & -0.27 \\
\hline 3 & 1.424 & 0.00 & 1.914 & -0.05 & 2.881 & -0.13 \\
\hline 4 & 1.758 & 0.47 & 1.980 & 0.09 & 2.803 & 0.02 \\
\hline 5 & 1.360 & & 1.910 & & 2.737 & \\
\hline 6 & 1.318 & & 1.877 & & 2.658 & \\
\hline 7 & 1.986 & 0.67 & 2.216 & 0.35 & 2.745 & 0.26 \\
\hline 8 & 0.556 & & 0.93 & & 1.447 & \\
\hline 9 & 1.964 & 0.90 & 2.231 & 0.77 & 2.963 & 0.78 \\
\hline 10 & 1.314 & & 1.53 & & 2.168 & \\
\hline 11 & 1.137 & & 1.485 & & 2.089 & \\
\hline 12 & 2.040 & 1.00 & 2.429 & 1.04 & 2.841 & \\
\hline 13 & 1.073 & & 1.392 & & 2.012 & \\
\hline 14 & 1.024 & & 1.373 & & 1.851 & \\
\hline 15 & 2.196 & 1.13 & 2.428 & 1.14 & 2.938 & 1.15 \\
\hline 16 & 1.046 & & 1.304 & & 1.777 & \\
\hline $1+2+3$ & 4.296 & & 5.852 & & 9.256 & \\
\hline $5+6+7$ & 4.665 & & 5.997 & & 8.141 & \\
\hline $1+2$ & 2.871 & & 4.037 & & 6.375 & \\
\hline $8+9$ & 2.530 & & 2.395 & & 4.410 & \\
\hline
\end{tabular}

$\triangle \mathrm{BE}(L)$ values correspond to the $\mathrm{Cu}$ atom binding energy difference in the first and in the second $\mathrm{Cu}$ atom layer. Positive values indicate that the adsorption on the second layer is favored.

Table 4

$\mathrm{BE}(L)$ values for $\mathrm{Cu}$ atom surface structures on $[\mathrm{Pt}(100)]_{25}$ hollow sites according to the sequential attachment numbers shown in figs. $5 \mathrm{a}-5 \mathrm{c} ; \triangle \mathrm{BE}(L)$ is defined in table 3

\begin{tabular}{|c|c|c|c|c|c|c|}
\hline \multirow{3}{*}{$\begin{array}{l}\mathrm{Cu} \text { atom } \\
L\end{array}$} & \multicolumn{6}{|c|}{ Electrode potential } \\
\hline & \multicolumn{2}{|l|}{$-0.6 \mathrm{~V}$} & \multicolumn{2}{|l|}{$0.4 \mathrm{~V}$} & \multicolumn{2}{|l|}{$1.0 \mathrm{~V}$} \\
\hline & $\mathrm{BE}(L)(\mathrm{eV})$ & $\Delta \mathrm{BE}(L)(\mathrm{eV})$ & $\mathrm{BE}(L)(\mathrm{eV})$ & $\Delta \mathrm{BE}(L)(\mathrm{eV})$ & $\mathrm{BE}(L)(\mathrm{eV})$ & $\Delta \mathrm{BE}(L)(\mathrm{eV})$ \\
\hline 1 & 2.460 & & 2.580 & & 3.367 & \\
\hline 2 & 1.920 & & 2.530 & & 3.230 & \\
\hline 3 & 1.880 & & 2.490 & & 3.210 & \\
\hline 4 & 2.380 & & 2.430 & & 3.100 & \\
\hline 5 & 1.770 & -0.60 & 2.380 & -0.32 & 3.050 & -0.35 \\
\hline 6 & 1.620 & -0.52 & 2.350 & -0.25 & 2.890 & -0.21 \\
\hline 7 & 1.100 & 1.26 & 2.060 & -0.04 & 2.676 & -0.01 \\
\hline 8 & 1.630 & & 2.118 & 0.11 & 1.447 & 0.12 \\
\hline 9 & 1.180 & & 1.110 & & 2.5 .50 & \\
\hline 10 & 2.530 & 1.59 & 2.400 & & 2.100 & \\
\hline 11 & 1.170 & & 1.660 & 1.31 & 1.890 & \\
\hline 12 & 2.730 & 1.79 & 2.460 & 1.07 & 2.940 & 1.09 \\
\hline 13 & 1.160 & & 1.550 & & 1.860 & \\
\hline 14 & 2.760 & 1.84 & 2.640 & & 1.850 & 0.07 \\
\hline 15 & 2.050 & & 1.230 & & 2.770 & \\
\hline
\end{tabular}


layer can grow simultaneously on $[\mathrm{Pt}(111)]_{24}$ leading to distinguishable bimetallic structures of similar energies (fig. 3), involving $\mathrm{Cu}$ atom aggregates of different sizes interacting with the substrate. In this case there is no univocal sequence for $\mathrm{Cu}$ atom adsorption. For $L$ smaller than or equal to the number of $\mathrm{Cu}$ atoms constituting the $\mathrm{Cu}$ monolayer, the attachment of the following $\mathrm{Cu}$ atoms leads to a heterogeneous surface consisting of $\mathrm{Cu}$ aggregates and bare $\mathrm{Pt}$ domains.

The subsequent location of $\mathrm{Cu}(5)$ on a site adjacent to a $\mathrm{Cu}_{4}$ pyramidal cluster cannot be directly determined by comparing the corresponding $\mathrm{BE}(L)$ value to that of $\mathrm{Cu}(1)$ adsorption on bare $[\operatorname{Pt}(111)]_{24}$ (table 3 ). However, a stable structure can be achieved by attaching three $\mathrm{Cu}$ atoms at sites adjacent to the $\mathrm{Cu}_{4}$ pyramidal cluster yielding a unique seven $\mathrm{Cu}$ atoms aggregate. This type of structure on $[\mathrm{Pt}(111)]_{24}$ is comparatively more stable than that consisting of two separate $\mathrm{Cu}_{4}$ and $\mathrm{Cu}_{3}$ clusters (table 3).

A similar calculation can be extended to the adsorption sequences $\mathrm{Cu}(1)$ and $\mathrm{Cu}(2)$, and $\mathrm{Cu}(8)$ and $\mathrm{Cu}(9)$ on $[\operatorname{Pt}(111)]_{24}$ (fig. 3). In this case the most favorable site for the adsorption of $\mathrm{Cu}(8)$ is one far from that occupied by $\mathrm{Cu}(7)$ in the bilayer structure. Because of the fact that $\mathrm{Cu}$ clusters of different sizes can be simultaneously formed on [Pt(111) $]_{24}$ the $\mathrm{Cu}_{5}$-based adsorption structures appear as the most likely ones.

Applied electric potentials which are set positive with respect to $E^{0}\left(\mathrm{Cu} / \mathrm{Cu}^{2+}\right)$ tend to stabilize the $\mathrm{Cu}$ monolayer domains. Otherwise, as the applied potential approaches $E^{0}\left(\mathrm{Cu} / \mathrm{Cu}^{2+}\right), 2 \mathrm{D}$ to $3 \mathrm{D}$ changes at the $\mathrm{Cu}$ monolayer leading to the lowest energy $\mathrm{Cu}$ adsorbate structures are favored through the rearrangement of electronic spins of $\mathrm{Cu}$ atoms (table 3). Therefore, the most stable structure implies the minimization of the total electronic spin (fig. 4).

The adsorption of $\mathrm{Cu}(5)$ on $\mathrm{a} \mathrm{Cu}_{4}$ hollow site formed on $[\mathrm{Pt}(100)]_{25}$ does not require the cancellation of unpaired spins as it is the case of a $\mathrm{Cu}_{3}$ hollow site on $[\mathrm{Pt}(111)]_{24}$. Structures almost similarly stable are achieved when either the $\mathrm{Cu}$ monolayer or a $\mathrm{Pt}-\mathrm{Cu}$ bilayer structure is grown on $[\mathrm{Pt}(100)]_{25}$ (fig. 5). In this case, nearly a similar decrease in $\mathrm{BE}(L)$ is attained by reorienting the

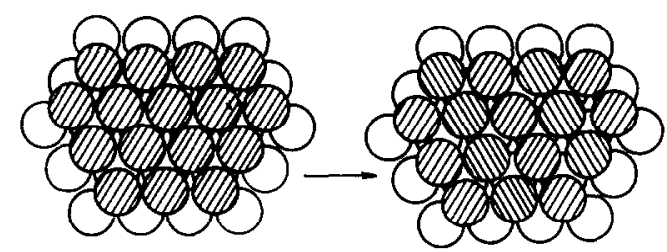

Fig. 4. Scheme of a Cu atom monolayer structure on $[\mathrm{Pt}(111)]_{24}$ surface. (a) Parallel spin $\mathrm{Cu}$ atoms arrangement, $E=$ $-5055.41 \mathrm{eV}$, (b) antiparallel spin $\mathrm{Cu}$ atoms arrangement, $E=-5066.87 \mathrm{eV} . E$ denotes the total energy of the $\mathrm{Cu}$ atom monolayer. spin down, spin up.

electronic spins of adsorbed $\mathrm{Cu}$ atoms (fig. 6). Incidentally, it should be noted that for $[\mathrm{Pt}(100)]_{25}$ the $\mathrm{Cu}$ monolayer is formed easier than for $[\mathrm{Pt}(111)]_{24}$. This fact can explain why $\mathrm{Pt}$ bare areas, probably constituted by $\mathrm{Pt}(111)$ domains, remain on polycrystalline Pt during Cu UPD [12].

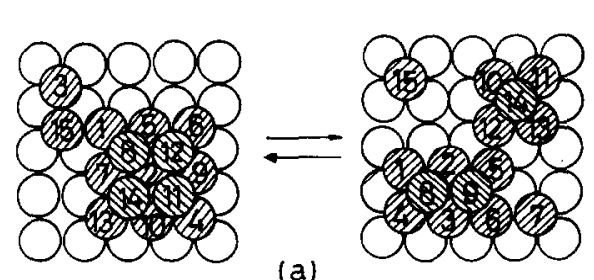

(a)

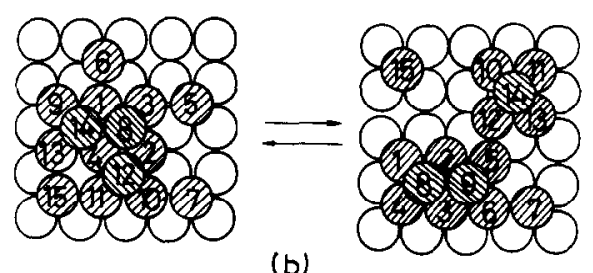

(b)

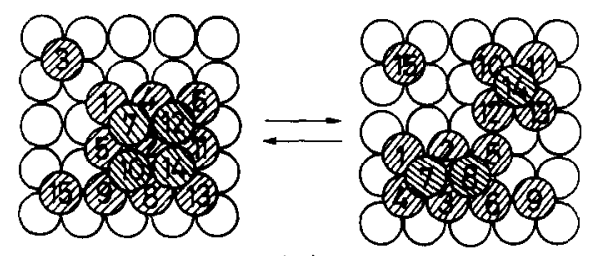

(c)

Fig. 5. Surface $\mathrm{Cu}$ atom (numbered and dashed circles) structures resulting on $[\mathrm{Pt}(100)]_{25}$ at different applied electric potentials. (a) $0.4 \mathrm{~V}$, (b) $1.0 \mathrm{~V}$, (c) $-0.6 \mathrm{~V}$. The numbers indicate the $\mathrm{Cu}$ atom attachment sequence. Possible $\mathrm{Cu}$ surface atom rearrangements are indicated. spin down, spin up. 


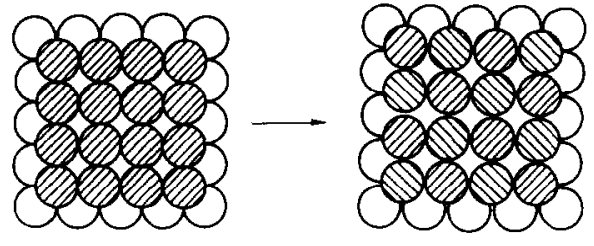

Fig. 6. Scheme of a $\mathrm{Cu}$ atom monolayer structure on $[\mathrm{Pt}(100)]_{25}$ surface. (a) Parallel spin $\mathrm{Cu}$ atoms arrangement, $E=$ $-4778.52 \mathrm{eV}$, (b) antiparallel spin $\mathrm{Cu}$ atoms arrangement, $E=-4787.18 \mathrm{eV}$. $E$ denotes the total energy of the $\mathrm{Cu}$ atom monolayer. spin down, spin up.

The application of a positive electric potential to $[\mathrm{Pt}(100)]_{25}$ also changes the $\mathrm{BE}(\mathrm{Cu}-\mathrm{Cu})$ in the direction of increasing the $\mathrm{Cu}$ monolayer formation (table 4) as for $[\operatorname{Pt}(111)]_{24}$. Otherwise, the application of a negative electric potential to $[\mathrm{Pt}(100)]_{25}$ turns out the growth of the $\mathrm{Pt}-\mathrm{Cu}$ bilayer structure easier than on $[\mathrm{Pt}(111)]_{24}$. Accordingly, a different $\mathrm{Cu}$ atom attachment sequence has to be considered.

\section{Comparison with experimental data}

There is experimental evidence [12] that $\mathrm{Cu}$ UPD on Pt electrodes in acid solutions implies the spontaneous and reversible formation of $3 \mathrm{D}$ $\mathrm{Cu}$ aggregates either just before or immediately after the completion of the $\mathrm{Cu}$ monolayer. The relaxation of $2 \mathrm{D} \mathrm{Cu}$ domains yields $3 \mathrm{D} \mathrm{Cu}$ aggregates at the substrate surface simultaneously with the appearance of bare $\mathrm{Pt}$ domains. The latter are revealed through the $\mathrm{H}$-adatom electrosorption process [12]. On the other hand, by setting the potential more negative than $E^{0}\left(\mathrm{Cu} / \mathrm{Cu}^{2+}\right)$ the formation of a $3 \mathrm{D}$ phase $\mathrm{Cu}$ atom overlayer is favored. Therefore, the $\mathrm{Pt}-\mathrm{Cu}$ bimetallic structures and $\mathrm{BE}(L)$ values resulting through the present calculations agree with the conclusions derived from electrochemical data.

Calculated data also show that the relaxation of the UPD Cu layer is facilitated on $\mathrm{Pt}(111)$ (fig. 6) as it also occurs on $\mathrm{Pt}(100)$, although for the latter, the spin reorganization is further assisted through the proper 2D initial Cu structures.
The applied electric potential modifies the relative $\mathrm{BE}(L)$ values of both $3 \mathrm{D}$ and $2 \mathrm{D}$ aggregates on both $[\operatorname{Pt}(111)]_{24}$ and $[\operatorname{Pt}(100)]_{25}$. Thus, at a sufficiently high positive potential the lower energy metal orbitals involved in the adsorption process favor the growth of $\mathrm{Cu}$ aggregates with several $\mathrm{Cu}$ atoms, but from the electrochemical standpoint this situation is counterbalanced by the most favorable ionization process of $\mathrm{Cu}$ atoms.

On the other hand, for applied electric potentials lower than $E^{0}\left(\mathrm{Cu} / \mathrm{Cu}^{2+}\right)$ the formation of highly stable bilayer structures takes place. In this case, the spontaneous rearrangement of the $\mathrm{Cu}$ structures at the monolayer level is accomplished on both $[\operatorname{Pt}(111)]_{24}$ and $[\operatorname{Pt}(100)]_{25}$.

\section{Molecular orbital interpretation}

The electronic configuration of $\mathrm{Cu}$ implies that the adsorption of $\mathrm{Cu}(1)$ on both $[\mathrm{Pt}(111)]_{24}$ and $[\mathrm{Pt}(100)]_{25}$ results in a reactive submonolayer with an unpaired electronic spin. The same situation arises for the adsorption of a single $\mathrm{Cu}$ atom on the stable $\mathrm{Cu}$ monolayer itself.

Otherwise, on $[\operatorname{Pt}(111)]_{24}$ for $L=3$, different submonolayer configurations can be produced which are characterized by either $(L-1)$ or $(L+$ 1) unpaired spins (fig. 7) offering at least two possible substrate structures after the adsorption of $\mathrm{Cu}(4)$. These examples show how the second $\mathrm{Cu}$ atom layer growth implies the appearance of the lowest energy surface structures. However, when adjacent $\mathrm{Pt}$ hollow sites are completely occupied by $\mathrm{Cu}$ atoms, the lowest energy configuration is attained through a reorganization of the $\mathrm{Cu}$ monolayer (fig. 7). In this case the greatest adsorbate stability corresponds to those configurations involving the lowest multiplicity due to the filling of the higher energy levels, driving the evolution of the system towards the mutual cancellation of spins.

On the other hand, on $[\operatorname{Pt}(100)]_{25}$ for $L=4$ configurations characterized by $(L-1)$ and $(L+$ 1) unpaired spins resulting from the adsorption of $\mathrm{Cu}(5)$ on either the second or the first adsorbate layer. The energy values resulting in this case are about 50 percent lower than that resulting for 


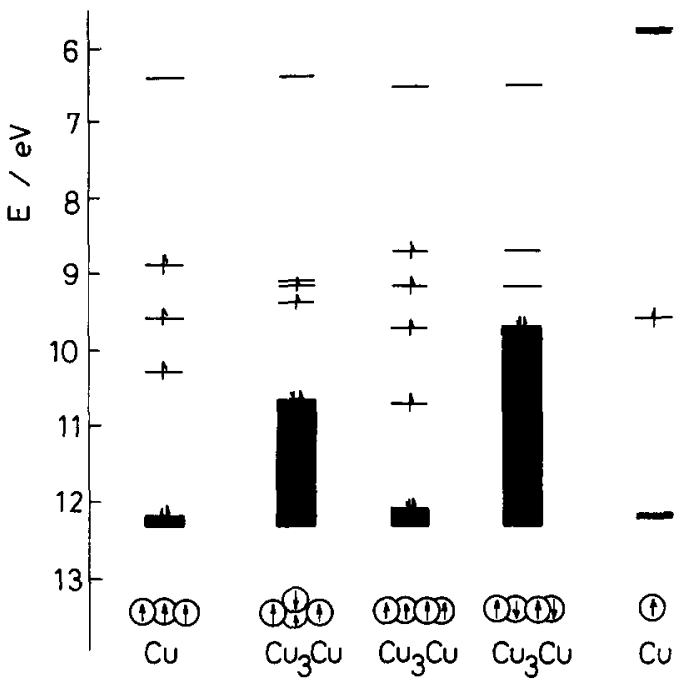

Fig. 7. Diagram of energy levels characterizing different electronic configurations associated with $\mathrm{Cu}$ aggregates on $[\mathrm{Pt}(111)]_{24}$.

$[\mathrm{Pt}(111)]_{24}$. Unfortunately, as the energy values of both adsorbate configurations are very close, it remains uncertain whether the second $\mathrm{Cu}$ atom layer starts to grow either before or after the $\mathrm{Cu}$ monolayer structure becomes stable.

\section{Discussion}

The preceding analysis indicates that orientation of the unpaired spins of $\mathrm{Cu}$ atoms plays an important role in determining the lowest energy configuration for the $\mathrm{Cu}$ atom overlayers on $\mathrm{Pt}$ single crystal structures.

Let us consider that $\mathrm{Pt}$ adsorption sites at well definied crystallographic faces are characterized by a closed shell structure (fig. 2). For $[\mathrm{Pt}(111)]_{24}$ the $\mathrm{Cu}(1)$ adsorption leads to a $\mathrm{Pt}_{3} \mathrm{Cu}$ adsorbate ensemble, the latter appearing as an adsorption site itself. Further incorporation of $\mathrm{Cu}$ atoms lead to two kinds of adsorption sites, namely $\mathrm{Cu}_{3}$ site with a multiplicity $m=4$ (three parallel electron spins), and $\mathrm{Pt}_{3}$ site defined by the close shell $\mathrm{Pt}$ atoms. These two kinds of sites which are considered as mutually independent, are competing for $\mathrm{Cu}(4)$ adsorption. When the latter occurs at a $\mathrm{Cu}_{3}$ site, an adsorbate structure with $m=3$ is produced, resulting from 2 parallel and 2 antiparallel electron spins. Otherwise, when $\mathrm{Cu}(4)$ adsorption takes place on a $\mathrm{Pt}_{3}$ site, an adsorbate structure with $m=5$ results from four parallel electron spins of adsorbed $\mathrm{Cu}$ atoms. The stability of these systems (fig. 7) increases by filling progressively the lower energy orbitals. Correspondingly, the total energy of the system decreases according to $m$.

On the other hand, for $[\mathrm{Pt}(100)]_{25}$ when either a $\mathrm{Cu}_{7}$ ensemble at UPD or a $\mathrm{Cu}_{6}$ ensemble at OPD (over potential deposition) has been formed (table 4), two kinds of adsorption sites are present, namely a $\mathrm{Cu}_{4}$ site with $m=5$ (four parallel electron spins), and a $\mathrm{Pt}_{4}$ site defined by close shell Pt atoms. These sites are competing for either $\mathrm{Cu}(8)$ or $\mathrm{Cu}(7)$, respectively. For the UPD-built $\mathrm{Cu}_{7}$ ensemble the adsorption of a $\mathrm{Cu}$ atom at a $\mathrm{Cu}_{4}$ site leads to an adsorbate structure with $m=7$ (six parallel and two antiparallel electron spins). Otherwise, $\mathrm{Cu}$ adsorption at sites adjacent to a $\mathrm{Pt}_{4}$-site increases $m$ to 9 (eight parallel electron spins of adsorbed $\mathrm{Cu}$ atoms).

Furthermore, when sites adjacent to $\mathrm{Cu}$ aggregates are occupied by $\mathrm{Cu}$ atoms with parallel electronic spins, the assumption that adsorption sites are equivalent and mutually independent ones, is no longer valid because of the strong interactions among adsorbed particles at distinguishable surface domains. In this case, the initial structure of $\mathrm{Cu}$ atom aggregate turns into a new one of lower energy produced through electron spin pairing. Accordingly, the multiplicity of the adsorbate ensemble appears again as the driving force for the $\mathrm{Cu}$ overlayer rearrangement. The mechanism of this process can be considered as a phase transition involving a magnetization change as the driving force assisting the rcordering of the adsorbate-substrate domains. The qualitative evaluation of this possibility, however, is beyond the abilities of the EHMO calculations [37,38].

\section{Acknowledgements}

This work was financially supported by the Consejo Nacional de Investigaciones Científicas y Técnicas of Argentina and the Comisión de In- 
vestigaciones Científicas de la Provincia de Buenos Aires. M.B. López acknowledges a fellowship from CONICET for the period 19891990.

\section{References}

[1] N. Furuya and M. Shibata, J. Electroanal. Chem. 266 (1989) 461.

[2] M. Shibata and N. Furuya, J. Electroanal. Chem. 269 (1989) 217.

[3] M. Shibata, N. Furuya, M. Watanabe and S. Motoo, J. Electroanal. Chem. 263 (1989) 97.

[4] J. Clavilier, A. Fernández Vega, J.M. Feliú and A. Aldaz, J. Electroanal. Chem. 258 (1989) 89.

[5] I.T.E. Fonseca, A.C. Marin and D. Pletcher, J. Electroanal. Chem. 218 (1987) 327.

[6] E. Schmidt and H. Siegenthaler, J. Electroanal. Chem. 150 (1983) 59.

[7] A. Bewick and B. Thomas, J. Electroanal. Chem. 85 (1977) 320 .

[8] A. Bewick and B. Thomas, J. Electroanal. Chem. 84 (1977) 127.

[9] B.S. Parajón Costa, C. Canullo, D. Vásquez Moll, R.C. Salvarezza, M.C. Giordano and A.J. Arvia, J. Electroanal. Chem. 244 (1988) 261.

[10] D.M. Kolb and R. Kötz, Surf. Sci. 64 (1977) 698.

[11] D.M. Kolb, A. Kötz and K. Yamamoto, Surf. Sci. 87 (1979) 20.

[12] D. Margheritis, R.C. Salvareza, M.C. Giordano and A.J. Arvia, J. Electroanal. Chem. 229 (1987) 327.

[13] R. Kubo, Statistical Mechanics, 1st ed. (North-Holland, Amsterdam, 1965) pp. 302-312.

[14] R.K. Pathria, Statistical Mechanics (Pergamon, Oxford, 1986) p. 87.

[15] L.E. Reichl, A Modern Course in Statistical Physics (Oxford Press, Oxford, 1980) pp. 106-120, 280-297.

[16] A.B. Anderson, J. Chem. Phys. 6 (1975) 1185.

[17] P.W. Selwood, Chemisorption and Magnetization (Academic Press, New York, 1975).

[18] R. Fournier and D.R. Salahub, Surf. Sci. 238 (1990) 330; F. Raatz and D.R. Salahub, Surf. Sci. 176 (1986) 219;
D.R. Salahub and F. Raatz, Int. J Quantum Chem. Symp. 18 (1984) 173;

R. Fournier and D.R. Salahub, Int, J. Quantum Chem. 29 (1986) 1077.

[19] R.J. Nichols, D.M. Kolb and R.J. Behm, J. Electroanal. Chem. 313 (1991) 109.

[20] J. Howell, A. Rossi, D. Wallance, K. Haraki and R. Hoffmann, FORTICON 8, Program No. 344, ECPE (Cornell University Press, Ithaca, 1977).

[21] G.L. Estiú, S.A. Maluendes, Z. Phys. Chem. (Leipzig) 271 (1990) 846.

[22] W. Lotz, J. Opt. Soc. Am. 60 (1970) 206.

[23] C.E. Moore, Atomic Energy Levels, NBS circular 467, National Bureau of Standards (US Government Printing Office, Washington, DC, 1958) pp. 115-123.

[24] E. Clementi and D.L. Raimondi, J. Chem. Phys. 38 (1963) 2686.

[25] E. Clementi and C. Roetti, At, Data Nucl. Data Tables, 14 (1974) 427.

[26] J.W. Richardson, W.C. Nieuwpoort, R.R. Powell and W.F. Edgell, J. Chem. Phys. 36 (1962) 1057.

[27] H. Basch and H.B. Gray, Theor. Chim. Acta 4 (1966) 367.

[28] L. Pauling, The Nature of the Chemical Bond, 3rd ed. (Cornell University Press, Ithaca, NY, 1960) p. 45.

[29] G.L. Estiú, S.A. Maluendes, E.A. Castro and A.J, Arvia, J. Phys. Chem. 92 (1988) 2512.

[30] G.L. Estiú, S.A. Maluendes, E.A. Castro and A.J. Arvia, submitted.

[31] G.L. Estiú, S.A. Maluendes, E.A. Castro and A.J. Arvia, J. Electroanal. Chem., submitted.

[32] A.B. Anderson and D.P. Onwood, Surf. Sci. 154 (1985) L261.

[33] A.B. Anderson and M.K. Awad, J. Am. Chem. Soc. 107 (1985) 7854.

[34] N.K. Ray and A.B. Anderson, Surf. Sci. 125 (1983) 803.

[35] M.B. López, G.L. Estiú, E.A. Castro and A.J. Arvia, J. Mol. Struct. (THEOCHEM) 210 (1990) 353.

[36] M.B. López, G.L. Estiú, E.A. Castro and A.J. Arvia, J. Mol. Struct. (TIIEOCIIEM) 210 (1990) 365.

[37] F. Pilar, Elementary Quantum Chemistry (McGraw-Hill, New York, 1968) pp. 584-644.

[38] H.S. Green and C.A. Hurst, Order-Disorder Phenomena, Monographs in Statistical Physics and Thermodynamics (Wiley, London, 1964) pp. 123-136. 